\title{
Simulation and Experimental Research on Robot Drilling
}

\author{
J.R.V. Sai Kiran, V.N.B Prasad Sodisetty
}

\begin{abstract}
This paper describes the experimental and analytical performance of robot drilling on alloy materials. In heavy structures manual drilling consumes time and quality of holes drilled is unstable. The industrial robot with agile motion is possible to machine a component. Industrial robots with high precision and six axis Degree of freedom are considered for better robot manufacturing processes. This work is to significantly improve performance of robot drilling over conventional drilling. The industrial manipulator used is $A B B$ IRB1410 with work volume of 2.6 meters and controlled by IRC5 Controller. Drilling machine utilized is specified with maximum speed of 3000 RPM. The speed of the drilling machine can be varied by voltage regulator and maintain different speeds at a difference of 100 RPM. The parameters like surface roughness, time consumed, circular entry and exit, roundness is considered. Relay is utilized to turn on/off the drill at the required places. The industrial manipulator robot and vertical CNC machine drillings are compared by random values of Design of Experiments. The process parameters like drill bit size, speed of drill and feed rate are considered. Conventional material removal techniques like CNC have been proven to be able to tackle nearly any machining challenge but major drawback of using conventional CNC machine is restricted work volume.
\end{abstract}

Keywords - CNC, Electrical drive, Robotic Drilling.

\section{INTRODUCTION}

In the past years, drilling was done physically utilizing only traditional methods. In computerization field, drilling was made obligatory for fabrication parts. Recent advancement in technologies has driven mankind towards automation. As a part of automation, drilling is a crucial part in machining operations. In this paper, a comparative study is drawn between robot drilling and $\mathrm{CNC}$ drilling. In routine material evacuation procedures $\mathrm{CNC}$ has ended up being ready to handle any machining challenge. However, the real disadvantage of utilizing CNC machines is the limited work volume. In theoretical perceptive, modern robot innovation could give a magnificent base to machining being adaptable. There exist few challenges in robot which limits its dominance in production sector. One of the challenges would be stiffness provided by the robot. During machining of any component there are various forces acting on the end effector, which reduce the machining quality. Response Surface Methodology is an optimizing technique and belongs to design of experiments strategy, where the study is concentrated on response produced by input parameters on drilling.

Revised Manuscript Received on July 10, 2019.

J.R.V. Sai Kiran, Department of Mechanical Engineering SRM saikiranjrv@gmail.com)

V.N.B Prasad Sodisetty, Department of Mechanical Engineering SRM Institute of Science and Technology, Chennai, T.N, India. (E-mail: bhavaniprasad.478@gmail.com) Institute of Science and Technology, Chennai, T.N, India. (E-mail:

Kalidas et al [1] investigated influences of drill temperature on hole quality under dry and wet drilling conditions. The results show that heat generated during wet drilling is less when compared to dry drilling, the hole quality also varies compared to both processes.

Alici [2] investigated drilling operation using a robot. A closed loop force control was the control scheme used. The results suggest that angular velocity and feed rate are two parameters with paramount importance. Robotic feed can only be determined after first iteration of machining.

Wong et al [3] presented the vision guided error measurement system in a robot for surgical drilling. The robot used lasers to maintain its position throughout the process. The laser would guide the end effector during machining, an error detected in the input of the light sensor would trigger a signal which would be compensated by the user.

Posada et al [4] presented a pragmatic approach to increase robot positional accuracy. An exterior sensory network technique is proposed for error reduction. The end effector was equipped with three proximity sensor which were used for sensing the linearity of spindle.

Bhagyashree et al [5] exhibited machining of an object using a gantry robot with perception ability, the end milling operation was performed and the result insisted that this robot generally develops error because of chatter and unexpected forces in primary machining direction.

In this paper the comparison study between robot drilling and CNC drilling is done. Different parameters like speed of drilling machine, feed rate and drill bit size are taken in to consider to check performance characteristics like surface finish or roughness, circularity entry and exit. Section 2 gives an overview of working setup. Section 3 describes about experimental results of robot drilling and $\mathrm{CNC}$ drilling. In section 4 Optimized results were given. This paper is concluded in Section 5 followed by References.

\section{INTERFACING ROBOT \& DRILLING MACHINE}

This section explains about interfacing drilling machine with robot. Speed regulator is utilized for varying speed and relay is utilized for turning the drill machine on/off at required places. The entire operation is done by robot in fully automatic mode.

\section{A. IRB 1410}

ABB IRB1410 robot is shown in the below fig.1.The robotic experiments are carried on ABB IRB1410 industrial

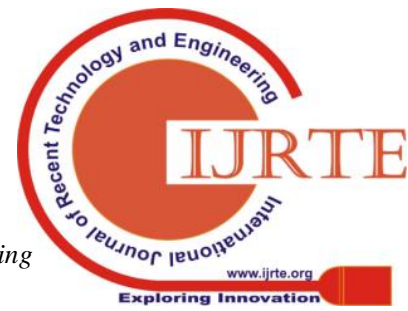


manipulator with controller IRC5, it is a student edition laboratory robot which has 6-axis of motion, with a payload of $5 \mathrm{~kg}$. It has maximum reach volume of 1.44 meters. This robot is capable of material handling, spray painting, Arc welding etc.

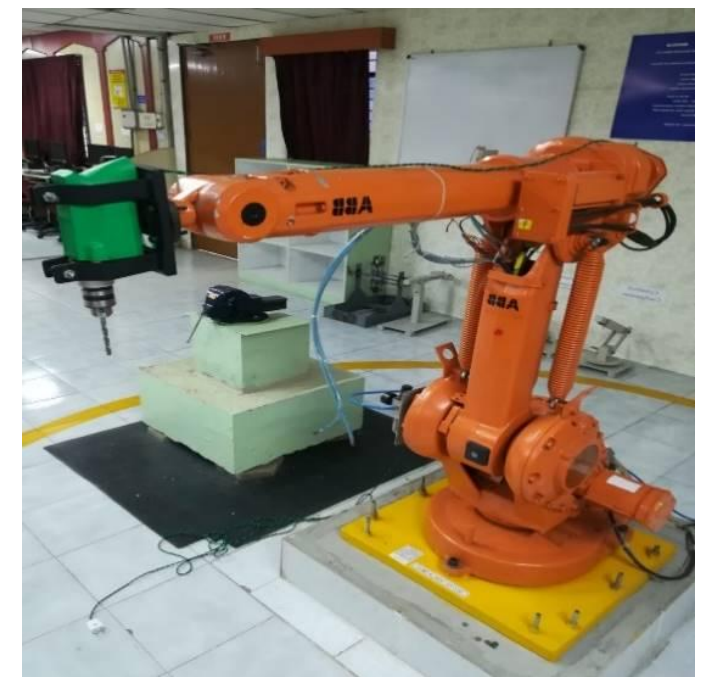

Fig. 1. Robot with Drilling Machine

\section{B. Drilling machine}

Electrical driven drill gun has a maximum spindle speed of 3000 RPM. In which drill bit size varies from $1 \mathrm{~mm}$ to 10 $\mathrm{mm}$. The frame which holds the drilling machine is shown in below fig. 2 .

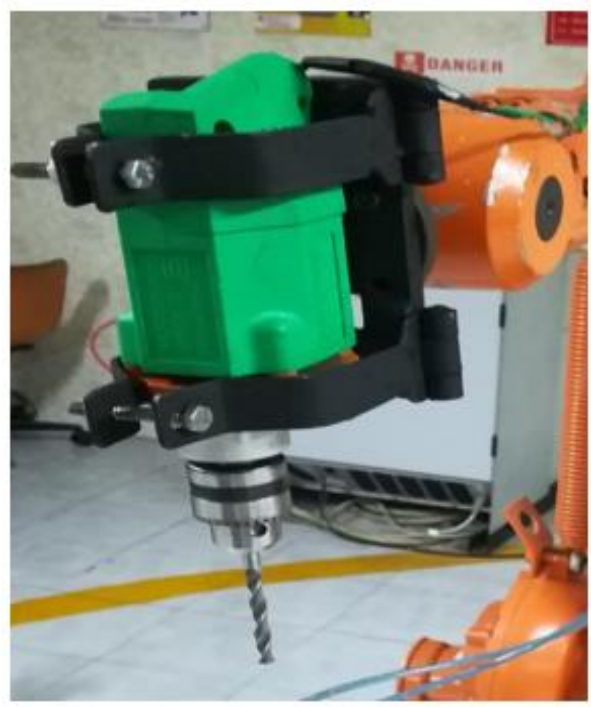

Fig.2 Drilling Machine Holding Frame

\section{CNC Machine}

It is a 3-axis vertical machining centre which has a heavy pay load of $400 \mathrm{Kg}$. Which has a reach work volume of 510 $\mathrm{mm}$ in $\mathrm{X}, \mathrm{Y}, \mathrm{Z}$ directions each. $\mathrm{CNC}$ is capable of drilling and milling operations. The machining centre has table size of $600 * 350 \mathrm{~mm}$. The positional accuracy is $0.001 \mathrm{~mm}$ and a maximum spindle speed of $8000(\mathrm{RPM})$.

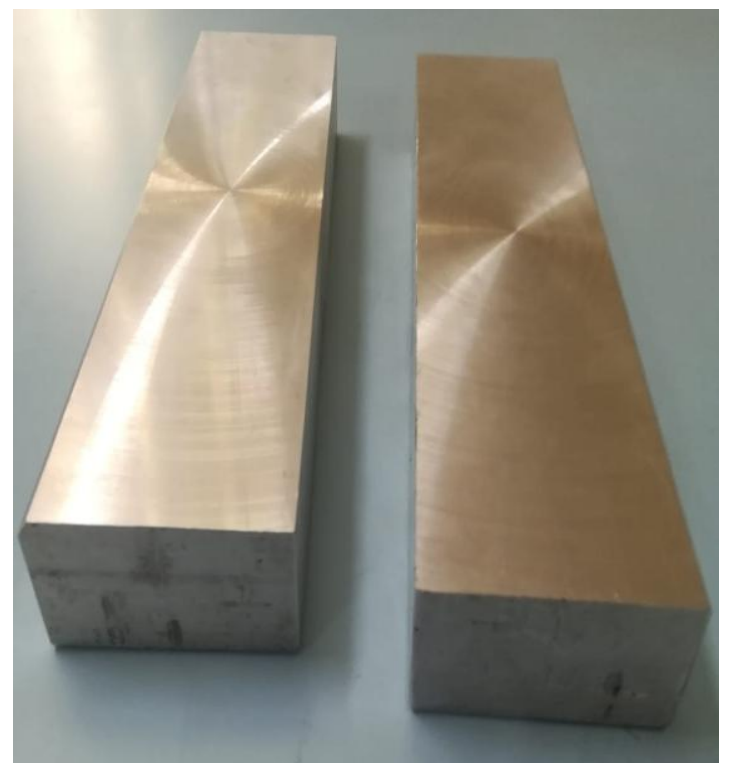

Fig.3 Workpiece (AL6061) Before Operation

\section{Relay Module}

REES52 relay module is utilized, it is a 4-channel relay output module. It is an electronically controlled switch. Relay input specifications are $24 \mathrm{~V}$ and 10A. Effective VCC, GND power input, can relay a separate power supply switch to on/off the power input of required component.

\section{E. Regulator}

Regulator is utilized to vary the speed of drilling machine from 0 to 3000 RPM. By varying the voltage supply, the speed of drilling machine keeps on changing.

The workpiece is a rectangle shaped Al6061 is shown in fig. 3 , having dimensions $200 \mathrm{~mm}$ length $50 \mathrm{~mm}$ breadth and a thickness of $25 \mathrm{~mm}$ is used. The workpiece used is HSS drill bit grade 42 of various diameters as mentioned below. The methodology involves experimental analysis of the machining process using industrial manipulator and vertical axis CNC machine.

In this system drilling machine is fitted with robot IRB1410. The robot manipulator end is fixed by an iron frame. A customized frame is utilized to hold the drilling machine with robot where drilling machine can be attached and detached. Input and Output signals from robot are utilized to on and off the drilling machine at required points. A relay is utilized to get the input and output signals and switch them to start or stop drilling machine. A speed regulator is used to vary the speed of drilling machine from 100 to 3000 RPM. Drilling process is done fully automatic mode using robot studio software. Number of operations are performed by varying different parameters like varying speed, feed and diameter of drill bit.

\section{EXPERIMENTAL ANALYSIS \& RESULTS}

Response Surface Methodology is a mathematical technique for empirical model building. The objective is to optimize a response which is influenced by several independent variables (input variables). Experiment is a 
series of tests, called runs, in which changes are made in the input variables in order to identify the reasons for changes in the output response. The application of Response Surface Methodology to design optimization is aimed at reducing the cost of expensive analysis methods and their associated numerical noise.

An important aspect of RSM is the design of experiments usually abbreviated as DoE. DoE parameters are shown in table I. Response surface are special standard experimental design that requires only a small number of experimental trials to find the main factors that effects on output. Response surface methodology experiments shown in table II.

TABLE I. DESIGN OF EXPERIMENTS

\begin{tabular}{|l|c|c|c|c|c|}
\hline $\begin{array}{l}\text { Process } \\
\text { parameter }\end{array}$ & $\begin{array}{c}\text { Level 1 } \\
(\mathbf{- 2})\end{array}$ & $\begin{array}{c}\text { Level 2 } \\
(\mathbf{- 1})\end{array}$ & $\begin{array}{c}\text { Level 3 } \\
\text { (0) }\end{array}$ & $\begin{array}{c}\text { Level 4 } \\
\text { (1) }\end{array}$ & $\begin{array}{c}\text { Level 5 } \\
\text { (2) }\end{array}$ \\
\hline $\begin{array}{l}\text { Y1 } \\
(\mathbf{m m})\end{array}$ & 6 & 7 & 8 & 9 & 10 \\
\hline $\begin{array}{l}\text { Y2 } \\
(\mathbf{r p m})\end{array}$ & 2000 & 2200 & 2400 & 2600 & 2800 \\
\hline $\begin{array}{l}\text { Y3 } \\
(\mathbf{m m} / \mathbf{m i n})\end{array}$ & 20 & 25 & 30 & 35 & 40 \\
\hline
\end{tabular}

Drill Bit $(\mathrm{mm})=($ Drill bit $(\mathrm{y} 1)-8) / 1$

Drilling speed $(\mathrm{rpm})=($ drilling $\operatorname{speed}(\mathrm{y} 2)-2400) / 200$

Drilling Feed $(\mathrm{mm} / \mathrm{min})=($ Drilling Feed $(\mathrm{y} 3)-30) / 5$

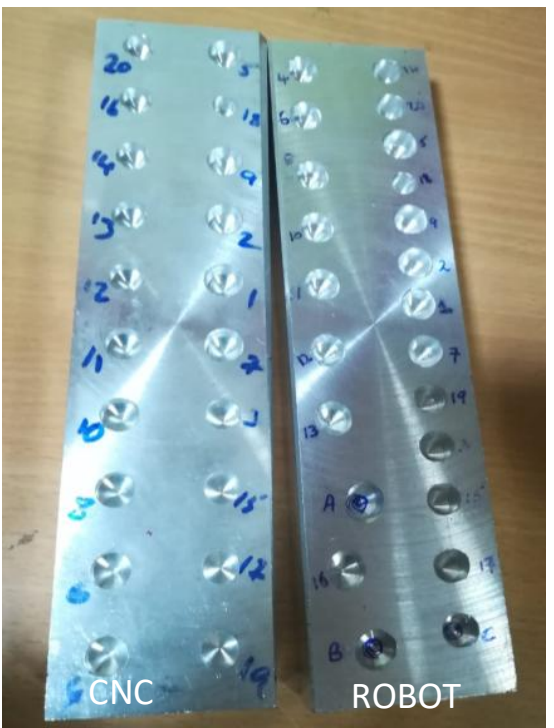

Fig.4 Workpiece (AL6061) After Operation

A comparative study has been done on the machining process in order to validate robotic drilling. A comparison is done between robot and conventional drilling. The below plot shows the comparison of roundness of the drilled hole of robot and $\mathrm{CNC}$ machine. It suggests that at low speed and moderate feed dimensions of the hole approach a good circle with a roundness of 0.02 . Until the process reaches the steady state the force increases and gradually reduce at steady state. So optimum speed at a lower feed rate required to obtain higher dimensional accuracy. Delay would be a new parameter in robotic machining which would significantly affect the performance characteristics. As delay increases roundness of the hole increases.
TABLE II. RESPONSE SURFACE METHODOLOGY

\begin{tabular}{|l|l|l|l|}
\hline Experiments & Y1 & Y2 & Y3 \\
\hline $\mathbf{1}$ & 1 & -1 & 1 \\
\hline $\mathbf{2}$ & 1 & 1 & -1 \\
\hline $\mathbf{3}$ & -1 & 1 & -1 \\
\hline $\mathbf{4}$ & 0 & 0 & 0 \\
\hline $\mathbf{5}$ & 2 & 0 & 0 \\
\hline $\mathbf{6}$ & 0 & 0 & 0 \\
\hline $\mathbf{7}$ & 1 & -1 & 1 \\
\hline $\mathbf{8}$ & 0 & 0 & 0 \\
\hline $\mathbf{9}$ & 1 & 1 & 1 \\
\hline $\mathbf{1 0}$ & 0 & -2 & 0 \\
\hline $\mathbf{1 1}$ & 0 & 0 & 0 \\
\hline $\mathbf{1 2}$ & 0 & 0 & -2 \\
\hline $\mathbf{1 3}$ & 0 & 0 & 2 \\
\hline $\mathbf{1 4}$ & 0 & 0 & 0 \\
\hline $\mathbf{1 5}$ & -1 & -1 & 1 \\
\hline $\mathbf{1 6}$ & 0 & 0 & 0 \\
\hline $\mathbf{1 7}$ & -1 & -1 & -1 \\
\hline $\mathbf{1 8}$ & -2 & 0 & 0 \\
\hline $\mathbf{1 9}$ & -1 & 1 & 1 \\
\hline $\mathbf{2 0}$ & 0 & 2 & 0 \\
\hline & & & \\
\hline
\end{tabular}

\section{ROBOT VS CNC}

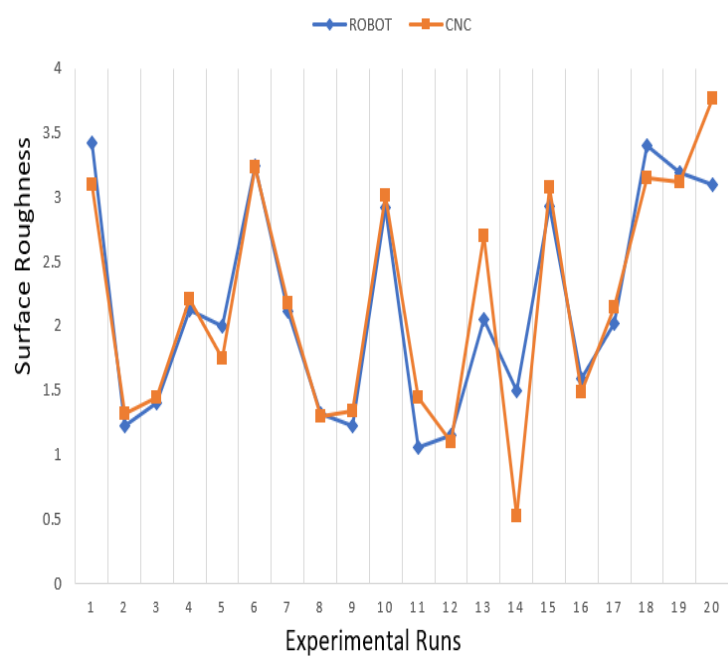

Fig.5 Comparison Graph for Surface Roughness

The shows the comparison of surface roughness and roundness of the drilled holes of robot and CNC machine are shown in fig. $5 \& 6$. Surface Roughness is another important parameter to be investigated. Surface roughness effects the lead time of the product. A higher machining in higher lead time which reduces the surface roughness as surface finish increases. In the comparative study done between conventional and robotic drilling, the surface roughness of robotic drilling was greater than conventional machining. This is due to the fact that slight vibrations that is robot is having $6 \mathrm{DOF}$ and 3 links in which vibration increases with addition of each link.

Published By:

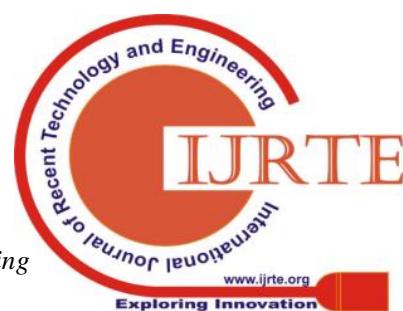




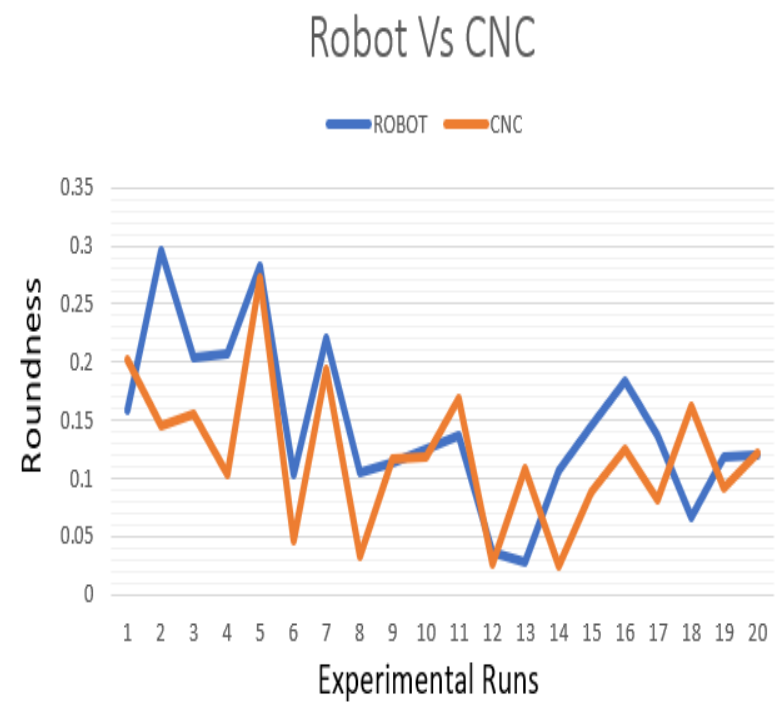

Fig.6 Comparison Graph for Roundness

\section{OPTIMIZATION}

The Minitab 17.0 student version is used to perform the Response Surface optimization. The optimized values for the giving performance measures are shown in fig. 7 .

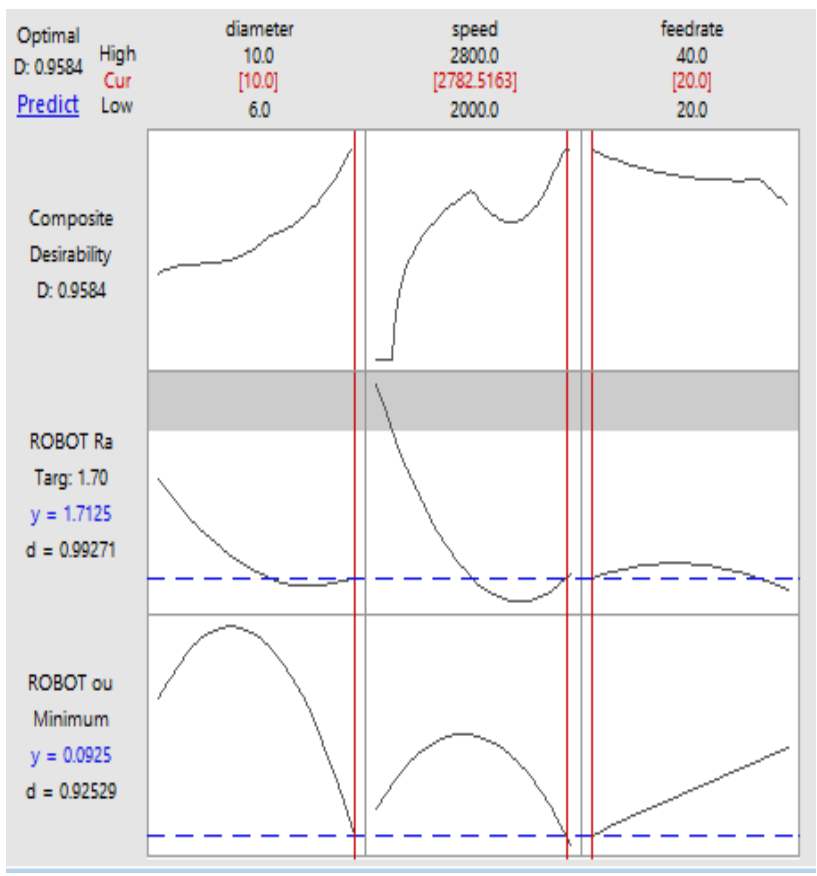

Fig.7 Optimization curve for given parameters

Response surface methodology is used to optimize the input parameters in order to get optimum and desired performance required are speed, feed rate and drill diameter. The objective characteristics are plotted. The optimization is done on responses of the process, the responses in the present process are Roundness and surface roughness. The optimum parameter required are speed of drilling, diameter of drill bit and feed rate. The objective function is to increase surface finish, accuracy and to minimize machining time.

\section{CONCLUSION}

The comparative study of drilling process using an industrial manipulator, Conventional machine suggests that the relative error of the performance characteristics is less than $6 \%$. In robotic drilling the reason for dimensional error is due to low stiffness of the end effector and at higher feed rate, high speeds the robot tends to have higher vibrations. Despite these phenomena the dimensional accuracy is satisfactory with a reasonable error. The suggests with a better end effector with higher damping capability, alloy like armoured steel and ballistic metals can be drilled using robot drilling which cannot be done using $\mathrm{CNC}$ machine and reduces lead time in manufacturing a heavy structure. A robot is capable of performing multiple operations like drilling, spray painting, welding, material handling and so on, where CNC will hold on only specific operation like drilling. But we cannot achieve higher accuracy rates with the robot as $\mathrm{CNC}$, as it is manufactured for sole purpose of drilling.

\section{REFERENCES}

1. Kalidas S, Devor RE, Kapoor SG.(2003), Experimental investigation of the effect of drill coatings on hole quality under dry and wet drilling conditions, Surface Coating technology, Vol. 148, pp. 117- 128.

2. G. Alici and R. W. Daniel, "Robotic drilling under force control: execution of a task", Intelligent Robots and Systems, vol.3,1994, pp. 1618-1625.

3. J. R. Diaz Posada, U. Schneider, S. Padan, M. Geravand, "High Accurate Robotic Drilling with External Sensor and Compliance Model based Compensation", IEEE International Conference on Robotics and Automation (ICRA), Stockholm, Sweden, May 16-21, 2016.

4. F.R. Wong1.S. Sharif , K. Kamdani , E.A. Rahim(2008). The Effect of Drill Point Geometry and Drilling Technique on Tool Life when Drilling Titanium Alloy, Ti-6Al-4V, Proceedings of International Conference on Mechanical \& Manufacturing Engineering (ICME2008 Johor Bahru, Malaysia.

5. Bhagyashree Das, M.R Stalin John,Machining A Component Using Vision Based 3-Axis Cartesian Robot, International Journal of Applied Engineering Research ISSN 0973-4562 Vol. 10,pp. 133-145.

6. T. Olsson, M. Haage, H. Kihlman, R. Johansson, K. Nilsson, A. Robertsson, M. Björkman, R. Isaksson, G. Ossbahr, and T. Brogårdh, "Cost-efficient drilling using industrial robots with high-bandwidth force feedback," Robotics and ComputerIntegrated Manufacturing, vol. 26, no. 1, pp. 24-38, 2010.

7. Sanjanna, Y. Bevish Jinila, "An Approach on Automated Rescue System with Intelligent Traffic Lights for Emergency Services", International Conference on Innovations in Information, Embedded and Communication Systems (ICIIECS 2015), pp. 1-5, IEEE 